\title{
humanidades
}

Revista humanidades

Julio-Diciembre, 2015 •Volumen 5, número 2・ISSN 2215-3934・pp. 1-16

\section{La pedagogía teatral y las TIC: Las nuevas TIC como apoyo en el aula universitaria}

DOI: http://dx.doi.org/10.15517/h.v5i2.21217

\section{Juan Carlos Calderón Gómez}

Máster, Coordinador de la Sección de Arte en la Escuela de Estudios Generales de la Universidad de Costa Rica.

Correo electrónico: calderon.juancarlos@gmail.com

Más sobre el autor:

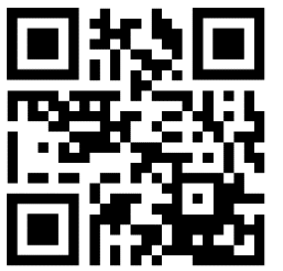




\section{La pedagogía teatral y las TIC: Las nuevas TIC como apoyo en el aula universitaria}

\section{Resumen}

La aplicación de las TIC en la preservación del material teatral para la enseñanza y la investigación en el aula, contribuyen a analizar detalladamente la complejidad del fenómeno teatral y su puesta en escena. Lo anterior al clasificar sus partes, analizar sus esquemas, sintetizar y proponer nuevos conocimientos.

Palabras clave: Teatro, pedagogía teatral, TIC.

\section{Theater pedagogy and ICT: ICT as new support in the university classroom}

\section{Abstract}

The application of ICT in the preservation of theatrical material for teaching and research in the classroom, contribute to analyze in detail the complexity of the phenomenon and its theatrical staging, the rated parts, analyze their schemes, and propose synthesizing new knowledge.
Keywords: Theater, theater pedagogy, ICT. 
"Estamos, xa que logo, diante dun campo de prácticas educativas, amplo e moi heteroxéneo, que teñen no teatro o seu eixe vertebrador e que van desde a formación académica regulada e sumamente formalizada ata experiencias sen apenas formalización. Un campo sumamente rico que mostra as potencialidades da educación teatral, na medida en que resulta posible educar con, desde, por, para e no teatro. Por iso queremos salientar, de partida, que cando falamos de formación ou de educación teatral non nos referimos en exclusiva á que sería propia de actores, actrices, directores e outros traballadores e traballadoras da escena, senón a ese rico e diverso campo de prácticas educativas que conforman o ámbito da educación teatral e o obxecto de estudo da Pedagoxía teatral"

Manuel Vieites

\section{La pedagogía teatral y las TIC}

El uso de la Tecnología Educativa como herramienta didáctica es relativamente reciente. Su incorporación en el aula no es del todo formalizada y sistematizada. Nuestra propuesta tiene que ver directamente con la formación del personal docente, con un modelo de política educativa que se

Las nuevas TIC como apoyo en el aula universitaria implante y una la teoría educativa que respalde esta práctica:

La Tecnología Educativa en sí misma no puede garantizar el convertirse en una herramienta eficiente en el ámbito educativo, sino que ello va a depender del paradigma educativo y de la pedagogía que se elijan, tanto como en la manera en que sea implementada en el ámbito didáctico... 
En esta época la Educación cuenta con un amplio espectro de posibilidades pedagógicas, debido al desarrollo de las propuestas paradigmáticas en Psicología. La claridad epistemológica es condición necesaria, aunque no suficiente, para una adecuada utilización de la Tecnología Educativa como herramienta didáctica. Como ejemplo de lo anterior están las nuevas propuestas psicogenéticas y sociocultural y las cognitivas, que al compartir la postura epistemológica constructivista, rompen de manera radical con el paradigma tradicional de corte conductista (Salas, 2002, p.17).

El protagonismo de las nuevas tecnologías es evidente en la era de la información y comunicación. Podemos afirmar que la aplicación de las TIC en la preservación del material teatral para la enseñanza y la investigación en el aula, contribuye a analizar la complejidad del fenómeno teatral; esto al clasificar sus partes, analizar sus esquemas, sintetizar y proponer nuevos conocimientos. Lo anterior no solo tomando en cuenta las desarrolladas en nuestro país, en Centroamérica y Latinoamérica, sino evidenciando su extraordinario potencial para compartir, conectar (se) ingresando a una comunicación planetaria, creando pensamiento complejo a través de su mismo navegar (Morin y otros, 2002).

El paradigma unidireccional de la educación propone el siguiente esquema de comunicación: emisor-mensaje-receptor. El hipertexto, por su esencia interactiva, propone un nuevo código de comunicación donde: 
(...) el mensaje no es emitido, no es un mundo cerrado, paralizado, inmutable, intocable, sagrado, sino un mundo abierto, modificable en la medida en que responda a los deseos del que lo consulta; así mismo el receptor no está ya en un posición de recepción clásica, pues es invitado a la libre creación, cobrando sentido el mensaje bajo su intervención (Silva, 2005, p. 17).

En la propuesta interactiva que ofrecen las TIC, la construcción del aprendizaje es el resultado de una posición dialógica, que asocia puntos de encuentro y posiciones antagónicas. Los discentes interactúan con los contenidos de aprendizaje como puntos de partida y no como puntos de llegada, construyendo sus propios mapas de conocimiento. Así, el profesorado propone el conocimiento no como verdad absoluta, sino como un facilitador de recorridos (Silva, p. 2005). O como propone Edgar Morin, cuando habla del método, que podemos asociar con el pensamiento hipertextual:

El método es un discurso, un ensayo prolongado de un camino que se piensa. Es un viaje, un desafío, una travesía, una estrategia que se ensaya para llegar a un final pensado, imaginado y al mismo tiempo insólito, imprevisto y errante. No es el discurrir de un pensamiento seguro de sí mismo, es una búsqueda que se inventa y se reconstruye continuamente (Morin y otros, 2002, p. 17). 
La propuesta del uso de las TIC en la enseñanza, no significa una tecnificación a ultranza dictada por el mercado. En la medida en que se popularicen los ordenadores, las modalidades presenciales y en línea coexistirán. En consecuencia, lo que hay que desarrollar es la inclusión digital del cuerpo docente para potenciar todos sus conocimientos al respecto, para que el objetivo de la enseñanza no sea transmitir conocimiento, sino crear estímulos para su creación autónoma y la constante ruptura con paradigmas culturales.

Salir "a la caza" de las puestas en escena en teatro, que mueren paradójicamente, en el mismo momento que nacen, ya no parece un trabajo absurdo o imposible de realizar, porque gracias a las TIC, el aula y otros espacios didácticos se han modificado considerablemente.

Implementando las TIC en el aula de teatro es posible fomentar el sentido de cooperación y curiosidad académica entre el estudiantado, ya que se abre un espacio para hablar sobre cómo el ser humano, al hacer teatro, crea y reflexiona sobre el tiempo que le ha tocado vivir, pero no solo como un documento histórico sino sociológico:

La historiología teatral implica la asunción epistemológica de esa pérdida, así como el desafío de "aventura" que significa salir a la busca de esa cultura perdida para describir y comprender su dimensión teatral y humana, aunque nunca para "restaurarla" en el presente (Dubatti, 2011, p. 53). 
La incorporación de los medios electrónicos al servicio del teatro y la evidente multiplicación de los canales y ámbitos mediáticos e intermediáticos, a través de la convergencia de los ordenadores y la telecomunicación en la red, hacen que el fenómeno teatral descubra nuevas posibilidades.

La incorporación de conceptos como virtualidad, conexión, multilinealidad e interactividad, incluidos en muchas de las nuevas producciones teatrales, han desplazado el paradigma que sitúa al texto escrito o literario como eje fundamental de la teatralidad, priorizando al texto espectacular sobre el escrito; desplazamiento que, indudablemente, tiene que ver con las transformaciones claves de la cultura postmoderna (Villegas, p. 2009).

Las nuevas manifestaciones de la teatralidad incorporan proyecciones manipuladas digitalmente, con la inclusión de robots, el planteamiento de una realidad virtual y de los performances que emplean tecnología telemática, entre otros. Esto es lo importante de esta investigación, ya que esos medios sirven para diseñar nuevas formas de preservación del fenómeno teatral y de replantear las lecciones de teatro, sobre todo las teóricas. $\left({ }^{1}\right)$

Las nuevas experiencias escénicas tienden a asociar el movimiento de los actores y actrices en el escenario con los sistemas móviles de iluminación, sonido y proyecciones. Lo anterior produce simultaneidad de pensamientos múltiples, producto de las nuevas tecnologías. En ese sentido, han variado notablemente las políticas y estrategias didácticas:

\section{La Pedagogía teatral y las TIC}


Por ello, se hace cada vez más necesario determinar las líneas ordenadoras de un conjunto organizado de decisiones didácticas y pedagógicas puntuales que permita al actor maniobrar con libertad expresiva en el interior del objeto teatral, en su dimensión actual (...). Cabría preguntarse aquí si el trabajo del actor; tal como lo hemos conocido hasta hoy, o sea, como el producto de un desarrolllo teatral fundamentalmente verbal (...) es capaz de sobrevivir en una sociedad occiental sometida a la presión que ejerce la dinámica intermedial (Thenon, 2002, p. 174).

Debemos señalar, sin embargo, como lo hace Graciela Alicia Snaola, que:

(...) estos espacios cognitivos propuestos por las TIC, han cambiado la "piel de la cultura," muchas veces limitan la actividad lúdica al entretenimiento, la lectura a la información, la enseñanza a la instrucción y el aprendizaje a la mera decodificación o entrenamiento (Esnaola, 2006, p. 15).

Estas limitantes mucha veces son producto no del uso de las TIC, sino del modo en que se estas tecnologías se programan y subutilizan en los procesos educativos.

Pulsar el fenómeno teatral es un acto histórico y sociológico al mismo tiempo. Valga mencionar que cuando hablamos de "nuevas tecnologías" al servicio del fenómeno teatral, no estamos preocupándonos por los efectos especiales (visuales, sonoros, táctiles), que acompañan algunas puestas en escena performáticas, como acabamos de señalar. Se trata pues, de un soporte informático para la conservación y acopio de la mayor cantidad de 
documentación teatral desarrollada por una puesta en escena (Urrutia, 2007) y contemplando el espacio virtual donde el estudiante sea capaz de almacenar esta información (a través de trabajos prácticos o del Trabajo Comunal Universitario) y pueda disfrutarla en su ordenador intercambiando información con pares.

Las nuevas tecnologías aplicadas al servicio de la archivística y la enseñanza del teatro han demostrado ser eficaces a la hora de rescatar al teatro del ostracismo temporal al que su carácter fugaz lo ha condenado. Jorge Dubatti se refiere al concepto de teatro comparado, relacionándolo con la cartografía teatral que elabora mapas específicos del teatro, desde las diferentes convergencias de las manifestaciones territoriales, no solo desde la literatura comparada -sostenemos nosotros-, sino desde las puestas en escena virtualmente establecidas:

El TC (Teatro/Comparado) sostiene inicialmente que estudiar el teatro desde un punto de vista internacional implica problematizar las relaciones e intercambios entre dos o más teatros nacionales (repertorios, poéticas e intertextos, ediciones, traducciones, viajes, etcétera), o entre un teatro nacional y cualquier cultura extranjera: externa a lo nacional (Dubatti, 2009, p. 102).

En el aula contaríamos con una base de datos propia y regional que nos permitiría estudiar nuestra producción escénica y establecer análisis comparativos con los demás países de la región, no solo a través del texto escrito, sino también desde otros elementos de la composición escénica y extraescénica como la técnica de la actuación; el movimiento escénico; el diseño escénico; el vestuario (colores, materiales, texturas, acabados); la escenografía, abstracta, funcional, expresionista 
o realista (fragmentada, exterior, interior, sugestiva); el maquillaje; los planos de luces; las bandas sonoras; la música empleada; la publicidad; y el diseño gráfico (salas, espacios escénicos, festivales, mapas de circuitos).

El análisis cartográfico que propone la comparación del fenómeno teatral y los estudios comparativos, ampliarían significativamente las propuestas dramáticas, fortaleciendo el concepto de multiculturalidad y estableciendo la idea de una conexión compleja y holística de infinitos matices teatrales.

Un ejemplo de lo anterior, se puede apreciar en la dinámica en línea propuesta por el Centro Latinoamericano de Creación e Investigación Teatral (CELCIT), con sede en Buenos Aires, Argentina, donde se programan cursos de teatro a través de la red (aulas virtuales, chat, correos), para personal docente, estudiantes y aficionados del teatro. La propuesta en línea para los meses de marzo a junio es: Gestión de públicos para las artes escénicas, profesora Silvia Peláez (México); Proyectos teatrales: Gestión y producción I, coordinado por Gustavo Schraier; Pedagogía teatral, una mirada posible I, bajo la tutela de Debora Astroski; Teatro latinoamericano del siglo XX, por Magaly Muguercia (Cuba); Análisis de la puesta en escena, realizado por Olga Cosentino; Taller de dramaturgia, dirigido por Ignacio Apolo; Dramaturgia orientada al teatro para niños y jóvenes a partir de textos literarios con el seguimiento, dictado por Lita Llagostera; y Claves para abordar el diseño escénico impartido, impartido por Jorge Ferro (Celcit, 2013). 
Podemos afirmar que la Revolución Científica Tecnológica produjo:

(...) contradicciones en el sistema educativo. En el campo de la educación estos vacíos aparecen no por la propuesta innovadora, democrática y globalizante de los recursos, sino más bien se instalan en la capacidad de cambio de los seres humanos. La dinámica de las estructuras tecnológicas arrastra, se quiera o no, la totalidad de las actividades de la cultura y de la civilización que se aleja del futuro como polo orientador de la vida individual y colectiva y se acerca a la predominancia del presente (Silva, 2005, p. 87).

Raúl Torres (2002) es enfático cuando señala que:

Todo lo que en la Red de redes puede disgregarse, desintegrarse y hasta prostituirse, en manos de la Universidad tiene posibilidades de beneficiar al ser humano (...) En manos de la Universidad, esta vieja aspiración puede tornarse real (Torres, 2002, p. 186)

La conservación de documentos que hicieron posible la puesta en escena incluyendo, pero no privilegiando el texto, es un trabajo urgente para que las fuentes se puedan referenciar. Así, la intervención de las TIC hace posible este rescate de una manera eficiente y eficaz, a pesar de que, como señala Juan Villegas (1999), los textos e intertextos presentes a nivel teatral también ofrecen dificultades: 
Con respecto al texto espectacular (...) es necesario reconocer que es más difícil la reconstrucción de la producción de otras prácticas escénicas, algunas de las cuales se han dado una vez y sobre la cual no se conservan documentos. La dificultad, sin embargo, no es sólo con respecto a textos de un pasado lejano sino que también es válida para el pasado inmediato y textos contemporáneos (Villegas, 1999, p. 191).

La incorporación de las TIC por sí mismas no garantiza la eficacia didáctica, depende de la relación establecida con el usuario y la persona que investiga. Quienes tienen acceso a la información con conocimientos sólidos previos y académicos tendrán mayores oportunidades de ser críticos frente al material encontrado y la forma de estudiarlo y relacionarlo con su entorno. El nuevo paradigma tecnológico- señala Torres (2003), permitirá un aprendizaje asincrónico, permanente, participativo y una nueva relación entre los actores.

Una nueva relación del cuerpo docente con el estudiantado en las aulas en ningún momento debe descartar la clase o taller presencial de la enseñanza del intérprete dramático, ya que puede acompañar el proceso de una manera guiada y supervisada. En las materias teóricas se puede convertir en una posibilidad inimaginable para lograr la atención del alumnado. 
Barberà, E. (2004). La educación en la red: Actividades virtuales de enseñanza aprendizaje. Barcelona: Paidós.

\section{Referencias}

bibliográficas

Boal, A. (1974). Teatro del oprimido y otras poéticas políticas. Buenos Aires: Ediciones de la Flor.

Burned, M. y otros. (1988). Master teachers of theatre. Observations on teaching theatre by nine American Masters. United States of America: Library Materials.

Celcit. (2013). Cursos a distancia. Recuperado de http://aulascelcit.com.ar

Delors, J. (1995). La educación encierra un tesoro. Informe a la UNESCO de la Comisión Internacional sobre la Educación en el Siglo XXI. Ediciones UNESCO. 1995. Recuperado de http://www.unesco.org/

De Tavira, L. (1999). El Espectáculo invisible: Paradojas sobre el arte de la actuación. Madrid: Publicaciones de la Asociación de Directores de Escena de España.

Dubatti, J. (2011). Introducción a los estudios teatrales. México D.F.: Libros de Godot.

Esnaola, G. (2006). Claves culturales en la organización del conocimiento. ¿Qué enseñan los videojuegos? Buenos Aires: Alfagrama Ediciones. 
García Huidobro, V. (2005). Pedagogía teatral. Metodología activa en el aula.

Santiago de Chile: Editorial Universidad Católica de Chile.

González, A. (2008). "Teatro y nuevas tecnologías: conceptos básicos”. Revista Signa, 17, pp. 29-56.

Ministerio de Educación de Chile (MINEDUC). (2007). Artes Escénicas.

Recuperado: htt://www.educrea.cl/otec/pdfs/instrumentos_curriculares PDF

Morin, Edgar., y otros. (2002). Educar en la era planetaria. Barcelona: Gedisa Editorial S.A.

Murria, Janet. (1997). "La pedagogía de la ficción cibernética: la enseñanza en un curso de lectura y escritura de narrativa interactiva”. En Barret, Edward y Marie Redmond: Medios contextuales en la práctica cultural: la construcción social del conocimiento. Barcelona: Editorial Paidós.

Robles, C. (2006). Drama holista. Arte del movimiento en el tiempo y el espacio. D.F.: Escenología, AC.

Rojas, E. (2011). Metodología de la Enseñanza de la Interpretación Teatral: algunos ejemplos. (Tesis inédita de Doctorado). Universidad Rey Juan Carlos. Facultad de Ciencias de la Comunicación. Instituto Superior de Danza Alicia Alonso. Máster Oficial y Doctorado en Artes Escénicas.

Salas, F. (2002). Epistemología, Educación y Tecnología Educativa. Revista Educación, 26, pp. 1 -18. San José: Universidad de Costa Rica. 
Schinca, M. y otros. (1997). La preparación del actor ciego. Madrid: Publicación de la Asociación de Directores de Escena de España.

SERNA, A. R. (1985). El método Didáctico. Recuperado de: http://aprendeenlinea.udea.edu.co/revistas/index.php/educacionfisicaydeporte /article/viewFile/4679/4112

Serrano, R. (2004). Nuevas Tesis sobre Stanislavski: fundamentos para una teoría pedagógica. Buenos Aires: Atuel.

Silva, M. (2005). Educación interactiva: Enseñanza y aprendizaje presencial y on-line. Barcelona: Gedisa Editores.

Stanislavski, K. (1977). El Trabajo del actor sobre su papel. Buenos Aires: Quetzal.

Stanislavski, K. (1999). La construcción del personaje. Madrid: Alianza.

Stanislavski, K. (2003). El arte escénico. Madrid: Siglo XXI.

Stanislavski, K. (2007). El trabajo del actor sobre sí mismo en el proceso creador de la vivencia. Barcelona: Alba Editorial.

Thenon. L. (2002). Proyectos de formación actoral: la formación del actor y la dramaturgia intermedial. Recuperado de: http://dialnet.unirioja.es/servlet/articulo? codigo $=270620$

Tomás, F. (1998). Escrito, pintado: Dialéctica entre escritura e imágenes en la conformación del pensamiento europeo. Valencia: La balsa de la medusa.

Torres, R. (2003). Los nuevos paradigmas en la actual Revolución Científica Tecnológica. San José: Editorial Universidad Estatal a Distancia. 
Urrutia, J. (2007). El teatro como sistema. Madrid: Biblioteca Nueva.

Villegas, J. (2009). Para la construcción del Teatro como construcción visual. California: Ediciones de Gestos.

Vieites, M. F. (2001). "Razón contra Furor. Genealogía y fundamentos de una Teoría de la Interpretación en Dedis Diderot”, ADE teatro, 87, pp. 23-31.

Vieites, M. F. (2004) Educación teatral e estudos de Arte dramática. Äreas de coñecemento, docencia e investigación. Implicacións para a function docente. En Arte dramática e función docente, pp. 15-138. Santiago de Compostela: Caride.

Murria H., Janet. (1997). “La pedagogía de la ficción cibernética: la enseñanza en un curso de lectura y escritura de narrativa interactiva". En Barret, Edward y Marie Redmond: Medios contextuales en la práctica cultural: la construcción social del conocimiento. Traducción del inglés por Laura Trafí. Barcelona: Paidós.

Todos los derechos reservados. Universidad de Costa Rica. Esta revista se encuentra licenciada con Creative Commons Reconocimiento-NoComercial-SinObraDerivada 3.0 Costa Rica.

Correo electrónico: humanidades.eeg@ucr.ac.cr / Sitio web: http://revistas.ucr.ac.cr/index.php/humanidades 